\title{
History of Holocene fluvial activity in Romania: evidences based on absolute dating
}

\author{
Maria Rădoane, Ioana Perșoiu, Francisca \\ Chiriloaei, Delia Robu, Nicolae Rădoane \\ Ștefan cel Mare University of Suceava \\ Suceava, Romania \\ radoane@usm.ro
}

\begin{abstract}
The main objective of this paper is to illustrate how was carried the reconstitution of geomorphological activity of rivers in Romania at different times of the Holocene based on the interpretation sedimentation contexts with dated samples, the sediment quality, their deposition styles, relict morphologies and others. The database compiled was processed using bivariate and multivariate statistical techniques or the probability distribution functions. The secondary objectives relate to: (i) Establishing a chronology of fluvial activity in Romania? (ii) How were felt Holocene climatic thresholds (identified in various proxies) in fluvial activity? (iii) How river chronology correlates with other environmental and geoarchaeological in our geographic area? (iv) In this research stage, we can explore some links with Central Europe fluvial chronologies?
\end{abstract}

Keywords - fluvial chronologies; absolute dating; probability density functions; Holocene

\section{APPROACHING PREMISES}

Regarding the knowledge evolution on fluvial landforms and processes, the year 2010 stands out as a reference year in grouping the study objectives: (i) before 2010, the fluvial geomorphology research has focused mainly on present-day and modern channel dynamics, on fluvial processes related to human impact and other driving factors; (ii) after 2010, many notable attempts have occurred, with studies focused on the better understanding of the style and of the magnitude of channels changes for different timescales (secular, millennial, Late Holocene, Holocene, Late Glacial and transition to Holocene). Over the last 6 years several scientific studies based on absolute dating were published, with results correlated with multidisciplinary investigations. Due to the increased number of references on past climate and hydrological events, geomorphologists wanted to correlate them with the magnitude of fluvial activity, responsible for the morphologic and sedimentologic adjustment styles of river channels. The required information are stored in sedimentary archives (litho-stratigraphic units whose morphological, granulometric, geochemical, biological characteristics indicate the mechanisms and physical processes which contributed to their deposition) and are dated by one of the known techniques. Because these structures are rich in biogenic material, the most used method to evaluate their age was radiocarbon dating.

\author{
Constantin Nechita \\ National Institute for Research and Development in \\ Forestry "Marin Drăcea" - INCDS, \\ Câmpulung Moldovenesc, Romania
}

In many regions of Europe absolute dating databases of the sedimentary archives were achieved, processed using the methodology elaborated by [1] and [2]. Thus, from Great Britain [3, 4], Spain [5], Germany [6] and Poland [7, 8], several hundreds of absolute dating of sedimentary archives were statistically approached and conclusions regarding the periods with high fluvial activity registered in the considered regions were obtained. In light of these results we want to report our own results throughout the objectives of the present study.

In Romania, significant progress was achieved as regards the chronology of the Holocene. [9] summed the palaeoclimatic data sources and climate reconstructions for the last 15000 years in Romania. The fluvial sedimentary archives (from floodplain and floodplain terraces) and sedimentary archives from small sedimentary basins (small lakes, peatbogs, swamps, glacial lakes) which are directly related with a drainage basin and network, were the main focus of our study. By approaching the meta-analysis technique, respectively, "the use of a systematic review procedure and common set of statistical techniques to combine the results of several studies" [10], we compiled a database of over 400 absolute dating collected from sedimentary units who had at source a hydrological event of a certain magnitude.

The aim of this work is the review of the existent records (published or in press), regarding the chronology of fluvial activity of Romanian rivers following some exceptional hydrological events. On this basis we intend to reconstruct the geomorphological fluvial activity of rivers in different moments of Holocene, to identify how some certain climatic thresholds were felt in the answer of fluvial processes, the role of human impact, correlation of other environmental and geoarchaeological chronologies from our geographical area.

\section{STUDY AREA AND THE DATABASE}

The compiled database totaled 404 stratigraphic units dated, distributed in Romania and across the border (in the case of Somes, Cris and Mures rivers). The data were collected from over 80 publications, and a large number of dates are provided by our research team (n 90). The samples are originating from fluvial environments adjacent to actual rivers or palaeo-paths 
located on floodplain or alluvial fans $(n=155)$ and lacustrine environments with direct connection to a drainage network $(n=249)$. Complementary, we have also used dendrochronological dating by using the dendrochronological information preserved in the subfossil trunks embedded in fluvial sediments. Also, we have considered 29 stands of living trees, Q. robur and $Q$ petraea distributed all over Romanian territory, which dendrochronological series with annual resolution helped us to detail the climatic conditions from 1800 until present.

Depositional environments that we followed were: palaeo-channels fills, riverbank deposits (lateral and vertical accretion), fluvial terraces (below $10 \mathrm{~m}$ relative altitude), colluvia, palaeosoils, wetland deposits within floodplains. The overview was completed with the inclusion of sedimentary units of small lakes and transitional peats and bogs located on the fluvial network.

The studied reaches were identified respect to river length from headwaters to the sampling point, relative altitude (compared to river bed elevation) and absolute altitude of the sampling place, the depth of sedimentary profile from which the sample was sampled, a short describing of the channel morphology, dated terrace height etc. There were 95 sites selected (Fig.1), within 1 site being inventoried from 1 to $11-19$ sedimentary structures dated.

Two river systems have been our focus for many years, through individual researches, within the research projects developed or $\mathrm{PhD}$ thesis elaborated, thus the higher density of the inventoried sites is represented by Somes River and its tributaries (35\%) and by Siret River and its tributaries (28\%). The other data concerns: Mures River and its tributaries, Tisa's tributaries, Danube, Teleorman, Olt. The obtained database was processed by using some specific statistical methods: cumulative curve of calibrated ages BP; probability density functions (PDFs) determination for variate datasets, statistical tests and sensitivity analysis.

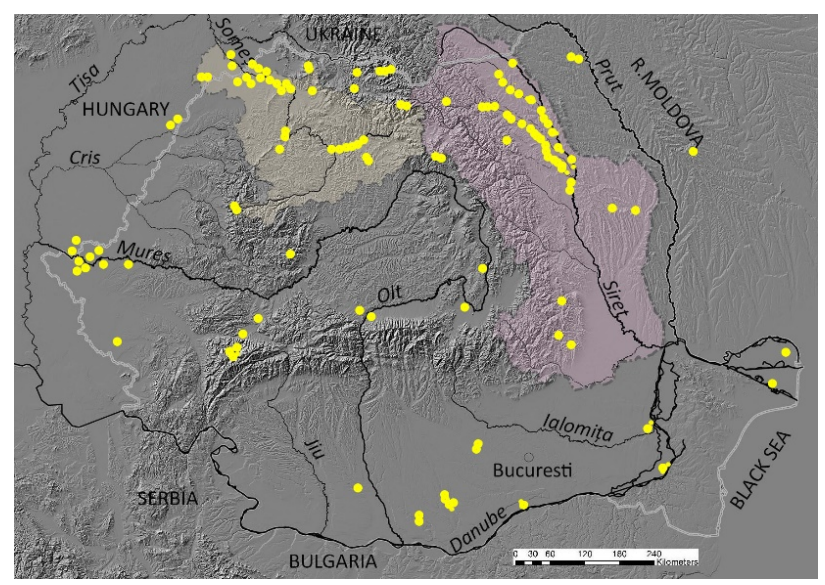

Fig. 1. The location of sites with absolute dating in: fluvial, limnological transition to fluvial network, and dendroclimatological environments. Siret and Somes drainage basins are identified by the higher density of absolute dating.

\section{RESUlTS AND DisCUSSIONS}

The graphical representation of calibrated ages of sedimentary units by using rank age curve (Fig. 2) does not represent a straight line. If the sedimentation rate in
Holocene, both in fluvial facies and lacustrine environment, should be uniform, then also the rank age curve would be a straight line. Actually, the existence of numerous episodes of increasing/decreasing of sedimentation rates determined a curving of successive distribution of rank ages. A higher curving is identified in the area of small ages also, given by the higher number of existent samples, then appear rhythm breaks all over the Holocene period and another bending of ages can be noticed towards the transition period from Early Holocene to Late Glacial.
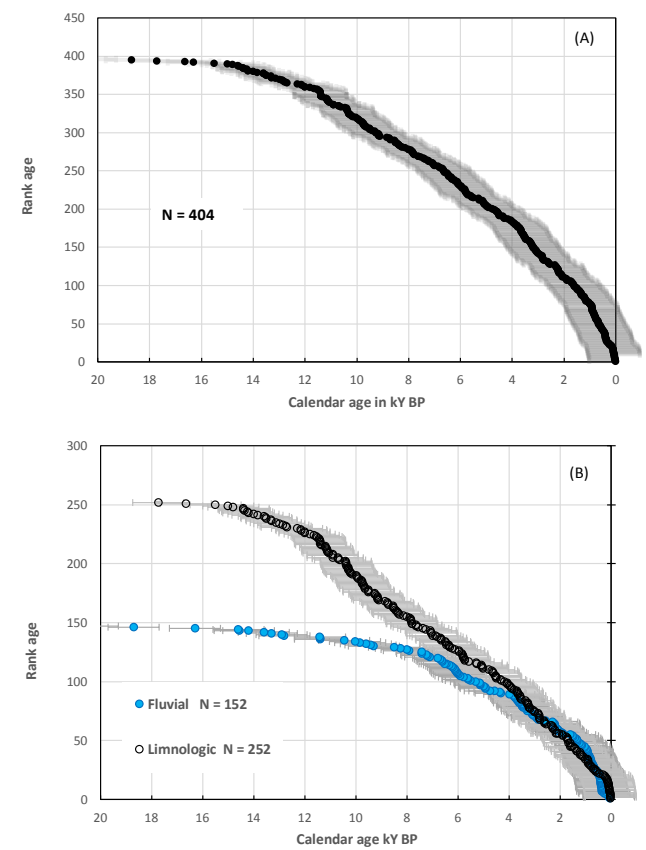

Fig.2. Cumulative curve of rank ages, showing the minimum and maximum ages and variation band of $2 \delta$ : A. Cumulative curve for all

data; B. cumulative curve for absolute dating dataset in fluvial environment (blue) and lacustrine environment related to fluvial one (black).

Data analysis of the two sedimentation areas shows a common trend of nonuniformity sedimentation, but which is more accentuated in the case of fluvial environment. At least for the ages older than $8 \mathrm{kyr}$, the rate of fluvial processes is changing, a possible cause could be the relative small number of data available for this period. Instead, in the lacustrine environment the sedimentation process displays a certain constancy (with small jumps), with the biggest change taking place towards the end of the Holocene.

For the last 7000 years, the interval where density of absolute age data is higher in fluvial domain from Romania, we have built the probability density functions curve (Fig. 3A) which shows that in some sequences of time, the probability that a change in sedimentation rate in certain floodplain facieses seems to be higher than in other sequences of time. For this geomorphologic process to take place, a flux water discharge of high magnitude was needed. This might have been the case of successive floods, capable to dislodging sediments from source area and to transport them towards the deposition zones.

Sediment accumulation in small sized lakes is very sensitive to dynamic processes from the supply basin (in this case the erosion and sediment transport in direct relationship to water discharges). We do not discuss here 
the combination of other factors driving the "cascade" of the listed processes.

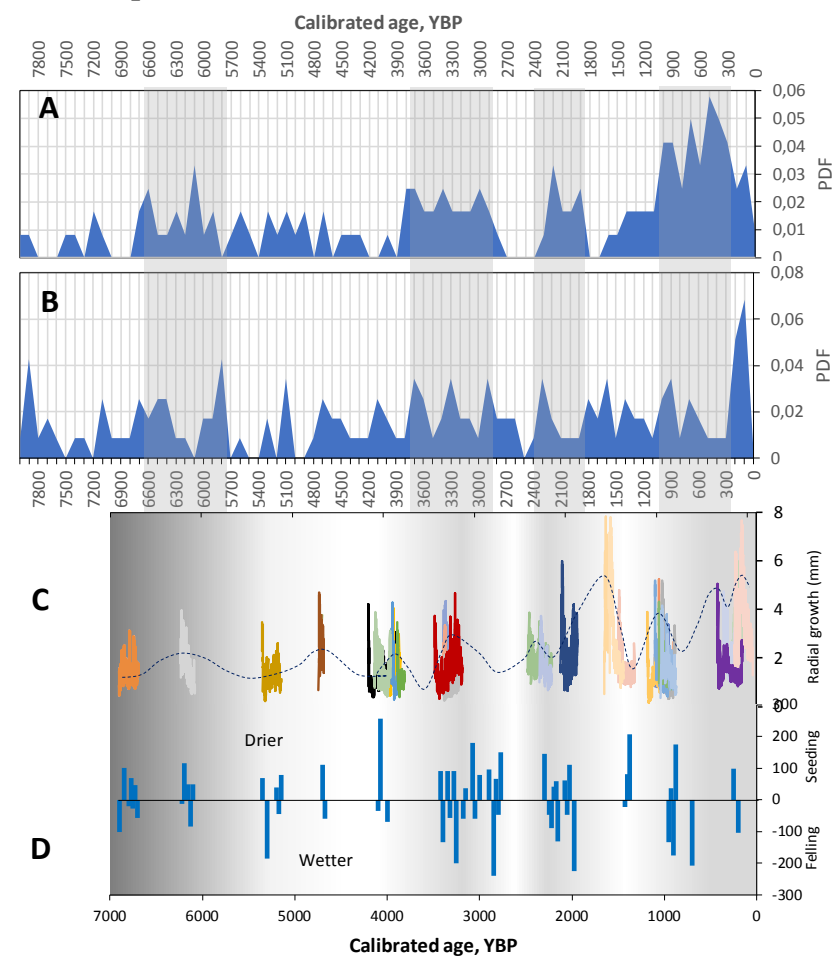

Fig.3. Probability density functions (PDFs) curves determined for the sedimentary units belonging to fluvial domain (A) and lacustrine domain (B) from Romania. Correlation of function parameters with radial growth for subfossil trunks originating from fluvial environment (C). Identification of humid periods (with potential for exceptional hydrological events) and dry periods on basis of dendrochronological sequences of subfossil trunks (D). The grey bends indicate the intervals with much intense hydro-geomorphological activity.

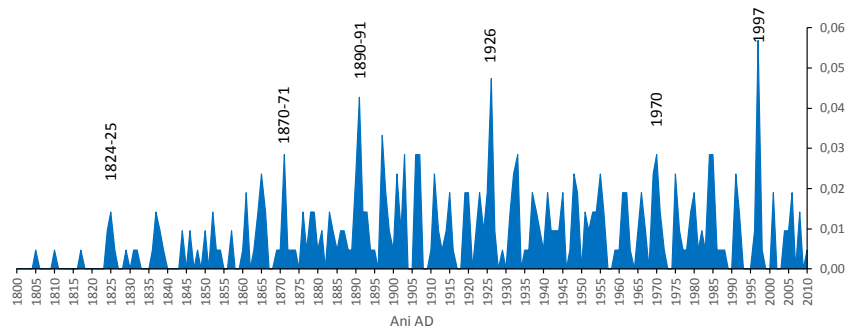

Fig.4. Years with excessive humidity during period 1800-2010, identified on basis of oak dendrochronological series of living trees from 29 stands distributed along Romania’s territory.

To note that the sedimentary sequences formed the basis of some time series were statistically addressed in the same manner of probability density functions (Fig. $3 B)$. Although in this case some specific groups of dated sedimentary sequences are observed, the peaks amplitude is much lower than in the fluvial domain. It is normal, considering that the lacustrine domain is much less turbulent, compared with the spatial discontinuities of the fluvial one.

In both temporal variations of PDFs several time intervals can be distinguished where the probability of achieving some hydro-geomorphological activity was higher, namely: 6600 - 5700; 3700-2900; 1900-2300; 1000-900 YBP. Over the last 700 years are visible the following intervals: 1200-1300AD, 1500-1600AD, 18001900AD. These intervals can also be identified at the level of subfossil trunks behavior, respectively, a large radial growth during humid periods (when the probability of registering exceptional hydrological events is higher than during dry periods when the trees have presented small radial growths) (Fig. $3 \mathrm{CDE}$ ).

The annual resolution offered by the dendrochronological investigations concerning the climatic elements (temperature, but especially precipitation) was the main reason for taking into consideration the information preserved in living trees with ages that reach the year 1800. The dendrochronological series processing allows the separation of pointer years when the tree has registered faithfully an excess of humidity or drought. In the followed context, we were interested by the years with humidity excess when the flood probability is maximum. The series of positive pointer years (Fig. 4) was addressed following the same technique, PDF analysis, and the result obtained completes in detail the information available for the last 200 years. Thus, the years with humidity excess identified, are: 1824-1825, 1870-71, 1890-91, 1926, 1970 and 1997 and were included in our final database.

The final conclusion of our paper is synthesized in Fig. 5. In this diagram was combined all the information compiled from our own researches and scientific publications regarding "changes data" [4] in fluvial and lacustrine environment sedimentation styles. The entire database $(n=404)$ was processed in the same manner using PDF analysis, for the last 12000 years. As the probability is higher, and the peaks of the variation curve are higher, in those intervals were focused more on exceptional events. On the contrary, a probability close to zero displays a reduced chance in that time interval to meet absolute dating data, respectively, changing sedimentation styles. On the diagram were indicated 15 peaks of the PDFs curve which indicate the time intervals with large hydrological events: 10300, 9800, 9200, 8500, 8000, 6790, 5650, 3750, 3300, 2850, 2350, 1500, 1300, 880,500 years BP.

The diagram from Fig. 4 is completed in its basal part with important events that have marked the sediment circuit on landforms surface. The large scale vegetation change at 10700 YBP (replacing the steppe with silvosteppe and forests [11], introduction of agriculture during early Neolithic, 8000-7500 YBP, the Stiucii Lake sequence revealed a continuous and consistent effect of human impact), [12] both with the already mentioned hydrological events, have determined optimum conditions for river channels (at least those on Siret and Somes sizes together with their important tributaries) changes of morphological style from braided to meandering.

In vertical plan, have been registered a general tendency of incision at that time being created the 4-5 m floodplain terraces. Climatic change reported around 4700 YBP determined an intensification of high magnitude hydrological events (as it is indicated also by the dendrochronology of subfossil trunks) that many reaches of river channels (especially those with Carpathian sedimentation source - Moldova Rivers being typical as regards this issue) were strongly filled with alluvium of 


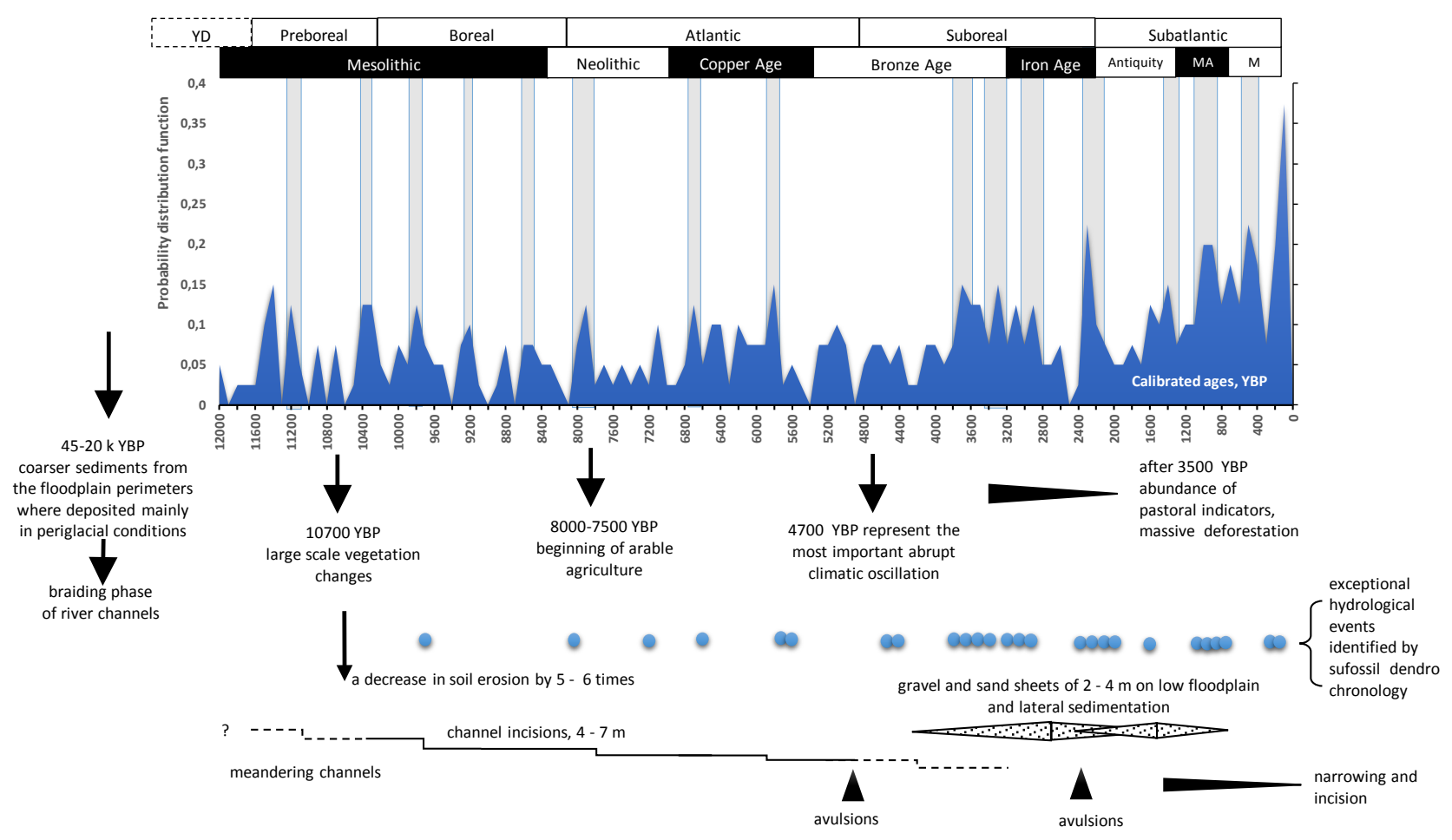

Fig. 5. Synthesis of sedimentation environments dynamics in Romania by using probability density functions. Interpreting the increased probability density with palaeo-environmental events reported for Holocene period (climatic oscillations, vegetation dynamics, human impact, palaeo-floods) The response reflected in river channel adjustments. Grey bands indicate the intervals with high probability that exceptional hydrogeomorphological events could occur

about 3-4 m thickness like a sheet of coarse gravel [13].

The meandered rivers, like Somes River located on the plain with the same name, have registered major course changes through the avulsion process (besides climatic factors, here intervened and the tectonic one [14]). Massive deforestations occurred after 3500 YBP (identified on basis of pastoral indexes from lacustrine sediments [11]) had its own contribution in expanding the alluvial or avulsion phenomenon on the rivers located in our geographical space.

The periods with major hydro-geomorphological events that we obtained, were compared with those reported for rivers in Central Europe (Tab. 1) and which followed the same methodological approach. It can be observed a very good concordance of the important peaks recorded for all three geographical regions. Four peaks (2850, 5650, 75008000 and 8500 YBP) were common in the databases for Germany, Poland and Romania; 11 from 15 peaks are common for the databases from Poland and Romania. Only for comparison, we have included the environmental evidence deduced on basis of a 12000-year proxy record in Stiucii Lake sediments located in Transylvanian Plain. We choose this example for its altitudinal position, very similar with one of the rivers for which we combined the data, thus, mitigating the influence of climatic natural setting.

In conclusion, for the first time in Romania a database containing 404 absolute dating data of some sedimentary units belonging to fluvial and lacustrine domains (the latter with direct connection to a fluvial network) was elaborated. The goal was to reconstruct the hydrologic and geomorphological activity phases of rivers. The working methods of data were based on a series of statistical tests and on obtaining the probability density functions curves. Fifteen phases of hydrogeomorphological activity were identified and have presented a high degree of synchronization (over 73\%) with the phases obtained in Poland and a medium one (over 47\%) with the phases determined for Germany.

TABLE I. PERIODS OF MAJOR FLOODING IN GERMANY, POLAND AND ROMANIA

\begin{tabular}{|c|c|c|c|}
\hline $\begin{array}{c}\text { Germany } \\
{[\mathbf{8}]}\end{array}$ & $\begin{array}{c}\text { Poland } \\
{[\mathbf{8}]}\end{array}$ & $\begin{array}{c}\text { Romania } \\
\text { (this study) }\end{array}$ & $\begin{array}{c}\text { Lake Ştiucii } \\
\text { proxy record } \\
{[\mathbf{1 2}]}\end{array}$ \\
\hline & $\mathbf{5 0 0}$ & $\mathbf{5 0 0}$ & $500-750$ \\
\hline $\mathbf{8 8 0}$ & $\mathbf{8 8 0}$ & \\
\hline $\mathbf{1 2 7 5}$ & & $\mathbf{1 3 0 0}$ & \\
\hline $\mathbf{2 3 2 5}$ & $\mathbf{1 5 0 0}$ & $\mathbf{1 5 0 0}$ & $1450-1550$ \\
\hline $\mathbf{2 8 2 0}$ & $\mathbf{2 8 5 0}$ & $\mathbf{2 3 5 0}$ & $1900-2200$ \\
\hline $\mathbf{3 3 5 0}$ & & $\mathbf{2 8 5 0}$ & $2600-2850$ \\
\hline & $\mathbf{3 7 0 0}$ & $\mathbf{3 3 0 0}$ & $3300-3600$ \\
\hline 4250 & & & $3950-4250$ \\
\hline & 4850 & & $4750-5000$ \\
\hline $\mathbf{5 6 9 0}$ & $\mathbf{5 6 0 0}$ & $\mathbf{5 6 5 0}$ & $5650-5900$ \\
\hline & $\mathbf{6 4 0 0}$ & $\mathbf{6 7 9 0}$ & $6750-7100$ \\
\hline $\mathbf{7 5 2 5}$ & $\mathbf{7 7 0 0}$ & $\mathbf{8 0 0 0}$ & $7900-8200$ \\
\hline $\mathbf{8 2 5 0}$ & $\mathbf{8 4 0 0}$ & $\mathbf{8 5 0 0}$ & \\
\hline $\mathbf{9 0 5 0}$ & & $\mathbf{9 2 0 0}$ & $9400-9550$ \\
\hline & $\mathbf{9 6 0 0}$ & $\mathbf{9 8 0 0}$ & \\
\hline & $\mathbf{1 0 2 0 0}$ & $\mathbf{1 0 3 0 0}$ & $10200-10500$ \\
\hline
\end{tabular}

\section{ACKNOWLEDGMENT}

The research was supported by a grant of the Romanian National Authority for Scientific Research and Innovation, CNCS - UEFISCDI, project number PN-II-RU-TE-20144-0855 "Reconstruction of Late Holocene History of 
Romanian rivers based on geomorphological and dendrochronological interpretation of subfossil trunks”.

\section{REFERENCES}

[1] M.G. Macklin and J. Lewin, "River sediments, great floods and centennial-scale Holocene climate change”, J. Quat. Sci., vol. 18, pp. 101-105, 2003.

[2] J. Lewin, M.G. Macklin, and E. Johnstone, "Interpreting alluvia archives: sedimentological factors in the British Holocene fluvial record”, Quat. Sci. Rev., vol. 24, pp. 1873-1889, 2005

[3] M.G. Macklin, G. Benito, K.J. Gregory, E. Johnstone, J. Lewin, D.J. Michezyńska, R. Soja, L. Starkel, and V.R. Thorndycraft, "Past hydrological events reflected in the Holocene fluvial record of Europe”, Catena, vol. 66, pp. 145-154, 2016.

[4] A.F. Jones, M.G. Macklin, and G. Benito, "Meta-analysis of Holocene fluvial sedimentary archives: A methodological primer", Catena, vol. 130, pp. 3-12, 2015.

[5] V.R. Thorndycraft and G. Benito, "The Holocene fluvial chronology of Spain: evidence from a newly compiled radiocarbon database”, Quat. Sci. Rev., vol. 25, pp. 223-234, 2006.

[6] T. Hoffmann, A. Lang, and R. Dikau,"Holocene river activity: analysing 14C-dated fluvial and colluvial sediments from Germany”, Quat. Sci. Rev., vol. 27, pp. 2031-2040, 2008.

[7] L. Starkel, R. Soja, and D. Michczynska, "Past hydrological events reflected in Holocene history of Polish rivers”, Catena, vol. 66, pp. 24-33, 2006.

[8] L. Starkel, D. Michczyńska, M. Krąpiec, W. Margielewski, D Nalepka, and A. Pazdur, "Progress in the Holocene chronoclimatostratigraphy of Polish territory”, Geochronometria, vol. 40, no. 1, pp. 1-21, 2012.

[9] A. Perșoiu, "Climate Evolution during the Late Glacial and the Holocene”, in Landform Dynamics and Evolution in Romania, M. Rădoane and A. Vespremeanu-Stroe, Eds., Springer, 2017, pp. 5766.
[10] M.G. Macklin, J. Lewin, and J.C. Woodward, "The fluvial record of climate change”, Phil. Trans. R. Soc. A, vol. 370, pp. 2143 2172, 2012.

[11] A. Feurdean and I. Tanțău, "The Evolution of Vegetation from the Last Glacial Maximum Until the Present”, in Landform Dynamics and Evolution in Romania, M. Rădoane and A. VespremeanuStroe, Eds., Springer, 2017, pp. 67-83.

[12] A. Feurdean, J. Liakka, B. Vannière, E. Marinova, S.M Hutchinson, V. Mosburgger, and T. Hickler, "12,000-Years of fire regime drivers in the lowlands of Transylvania (Central-Eastern Europe): a data-model approach”, Quaternary Science Reviews, vol. 81, pp. 48-61, 2013.

[13] M. Rădoane, C. Nechita, F. Chiriloaei, N. Rădoane, I. Popa, C Roibu, and D. Robu, "Late Holocene fluvial activities and relations with subfossil trunks: case study Moldova and Siret Rivers, Romania”, Geomorphology, vol. 239, pp. 142-159, 2015.

[14] I. Perşoiu, D. Robu, M. Rădoane, A. Perșoiu, B. Niga, F. Chiriloei, and N. Rădoane, in prep. "Late Glacial - Holocene subsidence in the NE Pannonian Basin (Ecedeea Plain) and its influence on fluvial drainage patterns”.

[15] I. Perșoiu and M. Rădoane, "Fluvial activity during the Holocene”, in Landform Dynamics and Evolution in Romania, M. Rădoane and A. Vespremeanu-Stroe, Eds., Springer, 2017.pp. 469-488. 